\title{
Transformações contemporâneas nas práticas jornalísticas: o jornalista on-line como mobilizador de audiência
}

\section{Adriana Barsotti}

\section{Resumo}

0 modelo de comunicação horizontal da internet deu voz a todos, pondo em xeque o papel do jornalista e reconfigurando suas funções. Este artigo analisou as rotinas produtivas nos sites dos jornais $O$ Globo e Extra para verificar como a web adicionou papéis a estes profissionais. 0 ponto de partida foi rever o estudo pioneiro de David White sobre o jornalista como gatekeeper na seleção de notícias. 0 conceito gatewatcher, que define 0 jornalista on-line como um observador à procura de conteúdos para seu público, também foi aplicado. Assim como a internet traz uma nova camada de informações ao jornalismo on-line, ela também superpõe camadas funcionais aos jornalistas. A crescente participação do público propõe novas funções aos profissionais na redação. A aposta teórica desta pesquisa é que o jornalista on-line está firmando sua identidade em um novo alicerce: 0 de mobilizador da audiência, atuando para engajar seu público em torno de diversas causas.

Palavras-Chave

Jornalismo on-line. Gatekeeper. Gatewatcher. Mobilizador.

Adriana Barsotti I barsotti.adriana@gmail.com Doutoranda do Programa de Pós-Graduação em Comunicação Social da Pontifícia Universidade Católica do Rio de Janeiro . Professora dos Cursos de Jornalismo do Instituto Brasileiro de Mercado de Capitais do Rio de Janeiro e da Escola Superior de Propaganda e Marketing - Unidade Rio.

\section{Introdução}

Quando Johannes Gutenberg criou 0

processo de impressão com tipos móveis, por volta de 1439, calculava-se que o acervo mundial de informações se reduzia a 30 mil manuscritos guardados em conventos e igrejas. Um século e meio após a invenção que permitiu a publicação do primeiro livro, a Bíblia, em 1452 - já havia 1,25 milhão de títulos publicados na Europa. Só os escritos de Martinho Lutero, impressos em 1517, alcançaram tiragens da ordem de $300 \mathrm{mil}$ exemplares (Mc GARRY, 1999).

Mais de cinco séculos depois, a internet gerou, em 2011, perto de dois zettabytes ${ }^{1}$ de conteúdo criado e compartilhado pelos usuários (MEEKER; WU, 2013). Só o YouTube registra o upload de cem horas de vídeo por minuto. ${ }^{2}$ Já chega a 500 milhões o número de fotos publicadas diariamente em redes sociais como o Facebook, Flickr, Snapchat e Instagram (MEEKER; WU, 2013). Os dois milhões de posts que blogueiros de todo o mundo publicam 
diariamente seriam suficientes para preencher por 770 anos a Revista Time. ${ }^{3}$

Nesta enxurrada de informações que trafegam pela web, qual papel será reservado ao jornalista? 0s meios de comunicação de massa não mais detêm o monopólio da produção da informação. 0s jornalistas passaram a dividir o saber de produção discursiva da notícia com seu público. Pesquisa realizada em 24 países mostrou que um quarto dos usuários de internet compartilham conteúdo - entre fotos, vídeos e links - na rede (MEEKER; WU, 2013). A internet favorece a comunicação horizontal, diferentemente dos veículos tradicionais, de comunicação vertical: é 0 modelo intercast (ou bottom-up news) versus o broadcast (ou top-down news), segundo definiram Bowman e Willis (2003). É dentro de um esquema horizontal, portanto, que a web reúne jornalistas, leitores, fontes e instâncias organizadas da sociedade.

Neste ambiente de superabundância informativa, o papel do jornalista é posto em xeque. Frente a uma crise de identidade jamais enfrentada, ele vem reconfigurando suas funções. Para verificar se e como a internet adicionou novos papéis a estes profissionais, foi realizada uma pesquisa etnográfica em 0 Glo- bo e no Extra - os dois maiores jornais do Rio de Janeiro em circulação e em audiência na internet - para analisar as rotinas produtivas de ambos no contexto de redações integradas. 0 ponto de partida foi rever 0 estudo pioneiro sobre a função do jornalista na seleção das notícias realizado por David White, em 1950, para verificar se persiste na internet o papel de gatekeeper do jornalista.

Embora tenha investido na hipótese de observação do gatekeeping na web, o estudo ganhou novos contornos. A pesquisa de campo permitiu ampliar a ambição inicial, contribuindo para que outras questões emergissem. Assim, além de verificar a pertinência do termo gatekeeping, analisei se os conceitos surgidos recentemente para definir a reconfiguração do papel do jornalista na internet, como 0 gatewatching (BRUNS, 2005) e 0 de mediador, agora reforçado pela web (CANAVILHAS, 2003; PALÁCIOS, 2003; SERRA, 2003), explicam a cultura profissional do jornalista on-line. A aposta teórica é que nenhum deles expressa isoladamente os valores compartilhados por essa comunidade interpretativa (TRAQUINA, 2005), pois na internet há uma superposição de funções. Por fim, foi sugerido mais um conceito para esse campo de estudos: 0 do jornalista como mobilizador da audiência na web.

Um zettabyte equivale a 1 trilhão de gigabytes.

Fonte: YouTube. Disponível em <http://info.abril.com.br/noticias/internet/por-minuto-100-horas-de-video-sao-postadas-noyoutube-19052013-11.shl>. Acesso em: 12 ago 2014.

Disponível em <http://www.businessinsider.com/everything-that-happens-in-one-day-on-the-internet-2012-3>. Acesso em 10 ago 2014. 


\section{Metodologia}

Fundado em 1925, 0 Globo é detentor da terceira maior circulação do Brasil, com uma média de 262 mil exemplares diários. ${ }^{4}$ A operação de $O$ Globo na internet teve início em julho de 1996. Hoje, entre os sites de jornais, está na segunda posição em número de leitores, com 6 milhões de visitantes únicos. ${ }^{5}$ Entre os frequentadores do site, $68 \%$ são das classes A e B. ${ }^{6} 0$ Extra é o quarto maior jornal do país, com uma média de 238 mil exemplares. ${ }^{7}$ A publicação estreou seu site apenas em 2007. A maioria de seus usuários compõem as classes B (59\%) e C (34\%). Entre os sites de jornais, 0 do Extra está na terceira posição em número de leitores, com 5,3 milhões de visitantes únicos, atrás da Folha de S. Paulo, com 7, 2 milhões, e de $O$ Globo. ${ }^{8} O$ Globo e o Extra - publicados pela mesma empresa, a Infoglobo Comunicações Ltda são hoje os dois maiores jornais do Rio de Janeiro.

Como interessava observar se o gatekeeping ainda é exercido no jornalismo on-line, a proposta inicial consistiu em adaptar e rever o método utilizado por David White em 1950, aplicando-0 aos sites dos dois jornais. White realizou seu estudo com um editor de primeira página, identificado como Mr. Gates, que trabalhava em um jornal norteamericano com tiragem de 30 mil exemplares numa cidade de cem mil habitantes. Em sua pesquisa, ele aplicou a teoria do gatekeeping para mostrar onde e em que ponto a ação de filtrar as notícias é exercida pelo editor. Após o fechamento da edição impressa, Mr. Gates deveria anotar os motivos pelos quais recusara as notícias que chegaram às suas mãos ao longo do dia. 0 estudo durou uma semana, após o qual White pôde contabilizar o número de notícias que passaram pelos gates ou filtros do editor.

Foi necessário atualizar o método neste estudo de caso. Adotei a observação participante nas redações de $O$ Globo e do Extra, partindo da premissa de que seria impossível aos editores das capas dos jornais on-line lembrarem-se de todas as razões para a recusa de notícias, tendo em vista 0 volume de informações que recebem ao longo de sua jornada de trabalho. Vale ressaltar que esses profissionais não são abastecidos apenas pelas agências noticiosas - como 0 era Mr.Gates -, mas principalmente pelos editores das diversas seções do site, pelos repórteres que estão na rua, pelos

Os números são do Instituto Verificador de Circulação (IVC) de 2010.

Os dados são do lbope NetView e referem-se a julho de 2011.

Os indicadores são do Google Analytics e referem-se a junho de 2014. Disponível em <http://anuncie.globo. Disponível em <http://www.businessinsider.com/everything-that-happens-in-one-day-on-the-internet-2012-3>. Acesso em 10 ago 2014.

Os números são do Instituto Verificador de Circulação (IVC) , referentes a 2011, e estão disponíveis no site da Associação Nacional de Jornais (ANJ): <http://www.anj.org.br/maiores-jornais-do-brasil>. Acesso em 13 ago 2014.

Os indicadores são do Ibope NetView e se referem a julho de 2011. Os dados foram fornecidos pela Infoglobo. 
blogueiros do jornal, pelos sites concorrentes, pelas emissoras de televisão e rádio, pelo conteúdo produzido pelo leitor e pelas redes sociais.

0 período de uma semana de pesquisa adotado por White foi restringido a uma semana útil (de 25/7 a 29/7 de 2011, em $O$ Globo; e de 30/5 a 3/6 de 2011, no Extra). A etnografia acompanhou a rotina das editoras de primeira página Cláudia Moretz-Sohn e Patrícia Sá Rêgo, respectivamente dos sites de o Globo e do Extra, durante quatro horas por dia, das $8 \mathrm{~h}$ às $12 \mathrm{~h}$. 0 recorte foi feito com base no fato de que é a partir das 8 h que os sites dos jornais começam a ser atualizados com mais frequência. Quando não há nenhum acontecimento de grande repercussão a ser noticiado, eles amanhecem refletindo praticamente a edição impressa do jornal. Entretanto, até o meio-dia, diversas primeiras páginas ou combinações delas já foram publicadas. Ou seja, já seria possível coletar material em abundância para a nossa pesquisa.

Cláudia tem 24 anos de experiência profissional, divididos entre redações de jornal, TV e sites e Patrícia tem dez anos atuando em sites jornalísticos, com uma breve passagem como repórter de jornal impresso. A rotina das duas tem início às 8 h. Enquanto checam as edições dos jornais impressos do dia, acessam simultaneamente páginas de sites noticiosos e prestam atenção ao noticiário da televisão e do rádio, que desde cedo já estão ligados. No mesmo horário, chegam os redatores responsáveis pela atualização das homes das diversas editorias. A partir daí, dá-se a "venda" das notícias por e-mail para elas. 0s e-mails já chegam com os links para as reportagens oferecidas para facilitar o trabalho de edição da capa. 0 ritmo frenético impede que a "venda" seja feita pessoalmente nas redações dos dois jornais.

Para a realização do estudo de caso foi combinada a mesma estratégia com Cláudia e Patrícia. Toda vez que recebessem um e-mail com uma "venda", elas 0 acusariam para que a contagem do total de notícias oferecidas pelos jornalistas no período pesquisado pudesse ser feita. Além da quantidade de notícias ofertadas, elas me informariam sobre o conteúdo das "vendas". A mim caberia observar se as notícias seriam aproveitadas na capa do site. Elas também deveriam avisar quando ocorressem atualizações nas homes. Ao fim das quatro horas diárias, as notícias recusadas eram contadas e a lista era apresentada a elas. As editoras então explicavam as razões pelas quais elas não haviam sido publicadas.

A necessidade de rever a teoria do gatekeeping é anterior à internet. Uma das conclusões da pesquisa de White (1999, p. 145) era de que a edição das notícias estava sujeita a "juízos de valor baseados na experiência, atitudes e expectativas do gatekeeper". Cinco anos após a pesquisa, o sociólogo norte-americano Warren Breed publicou um artigo no qual atribuiu peso maior das decisões jornalísticas aos valores editoriais da empresa e à rotina profissional das redações do que às crenças pessoais do jornalista. 
Em pesquisa com 120 jornalistas nos EUA, ele constatou que os profissionais afirmavam aprender a linha editorial da empresa "por osmose" (BREED, 1999, p. 155).

Analisando 0 artigo de Breed, Traquina (2005, p. 159) comenta que "devido aos custos e à lógica do lucro, são impostos constrangimentos ao trabalho jornalístico pelo orçamento da empresa". Ou seja, o gatekeeping seria exercido no contexto do ambiente organizacional. Entendemos, portanto, que o processo de seleção das notícias não é uma ação pessoal do gatekeeper. 0s "gates" - que se configuram como áreas de decisão - são regidos pelos critérios de noticiabilidade. Mas esses critérios resultam de uma articulação entre a cultura profissional dos jornalistas - com suas normas técnicas e prescrições éticas ,- os constrangimentos organizacionais, as rotinas produtivas da empresa jornalística e a relação estrutural entre a mídia e as fontes de informação, com suas posições institucionais.

\section{0 jornalista on-line como gatekeeper}

Ao longo dos sete dias, apenas 21,9\% das notícias "vendidas" pelos editores não foram publicadas na capa de $O$ Globo (Tabela 1). Ou seja, uma média de 10,2 por dia durante o horário pesquisado, diferentemente do Mr. Gates de White, que aproveitou somente um décimo das notícias que passaram por seu "portão", recusando, portanto, 90\% delas. No Extra, o índice foi semelhante: somente $19,1 \%$ das notícias oferecidas pelos redatores não foram publicadas na capa do site (Tabela 2). A constatação foi de que a quantidade de notícias que não é publicada nas homes dos sites é irrelevante. Embora também haja limitação de espaço nas capas dos sites, ela é mínima se comparada à dos jornais impressos. Enquanto na primeira página de $O$ Globo é possível encaixar, em média, 15 chamadas, na capa do site há espaço para cerca de 55. № Extra, cabem em torno de 10 chamadas no jornal impresso e 25 no site. Um dos maiores desafios do Mr. Gates pesquisado por White (1999, p. 145), ao contrário, era justamente a limitação de espaço,

Tabela 1 - Índice de aproveitamento das notícias na capa de 0 Globo*

\begin{tabular}{|c|c|c|c|c|}
\hline Dia & $\begin{array}{c}\text { Notícias } \\
\text { "vendidas" }\end{array}$ & Notícias recusadas & Notícias publicadas & Índice de aproveitamento \\
\hline $25 / 7$ & 53 & 14 & 39 & $73,6 \%$ \\
\hline $26 / 7$ & 42 & 7 & 35 & $83,3 \%$ \\
\hline $27 / 7$ & 53 & 9 & 44 & $83 \%$ \\
\hline $28 / 7$ & 41 & 10 & 31 & $75,6 \%$ \\
\hline $29 / 7$ & 44 & 11 & 33 & $75 \%$ \\
\hline TOTAL & $\mathbf{2 3 3}$ & $\mathbf{5 1}$ & $\mathbf{1 8 2}$ & $\mathbf{7 8 , 1 \%}$ \\
\hline
\end{tabular}

*A tabela foi construída a partir da contagem das notícias "vendidas" para o editor da home de 0 Globo e da observação das que foram por ele publicadas na capa do site entre os dias 25/7 e 29/7 de 2011, no horário de $8 \mathrm{~h}$ às $12 \mathrm{~h}$. 
Tabela 2 - Índice de aproveitamento das notícias na capa do Extra*

\begin{tabular}{|c|c|c|c|c|}
\hline Dia & $\begin{array}{c}\text { Notícias } \\
\text { "vendidas" }\end{array}$ & Notícias recusadas & Notícias publicadas & Índice de aproveitamento \\
\hline $30 / 5$ & 25 & 4 & 21 & $84 \%$ \\
\hline $31 / 5$ & 30 & 7 & 23 & $76,6 \%$ \\
\hline $1 / 6$ & 33 & 1 & 32 & $96,9 \%$ \\
\hline $2 / 6$ & 43 & 12 & 31 & $72 \%$ \\
\hline $3 / 6$ & 37 & 8 & 29 & $78,3 \%$ \\
\hline TOTAL & $\mathbf{1 6 8}$ & $\mathbf{3 2}$ & $\mathbf{1 3 6}$ & $\mathbf{8 0 , 9} \%$ \\
\hline
\end{tabular}

*A tabela foi construída a partir da contagem das notícias "vendidas" para o editor da home do Extra e da conferência das que foram por ele publicadas na capa do site entre os dias $30 / 5$ e $3 / 6$ de 2011 , no horário de $8 \mathrm{~h}$ às $12 \mathrm{~h}$.

a dificuldade de fazer escolhas de umas notícias preterindo outras. Nada menos do que 168 vezes o Mr. Gates faz a anotação 'sem espaço'. Resumindo, a notícia (aos seus olhos) tem mérito e interesse, ele não faz quaisquer objeções pessoais a elas, mas o espaço tem um valor superior.

A pouca limitação de espaço na internet se reflete na elasticidade dos filtros noticiosos, ou gates, aplicados pelos jornalistas on-line. "A possibilidade de dispor de espaço ilimitado para a disponibilização do material noticioso é, a nosso ver, a maior ruptura a ter lugar com 0 advento da web como suporte midiático para o jornalismo" (PALÁCIOS, 2003, p. 82). Para Serra (2003, p. 3940), essa característica da web pode levar a uma democratização na publicação, ao permitir acesso ilimitado à informação.

A ausência, pelo menos teórica, de limites de espaço ou de tempo de uma notícia ou de um artigo pode fazer com que o jornalismo deixe de ser aquilo a que alguns se referem como sendo a mera 'arte' de preencher os espaços e/ou os tempos deixados vazios pela publicidade.
Embora o processo de gatekeeping tenha sofrido corrosão na web, há motivos para afirmar que ele não foi eliminado do processo de publicação. Dados da observação do trabalho das duas editoras revelam de que maneira ele ainda é exercido dentro do contexto da cultura profissional dos jornalistas, que elegeu para si mesma "valores-notícia" para definir o que se enquadra nos critérios de noticiabilidade. Para Wolf (2009, p. 190), "noticiabilidade corresponde ao conjunto de critérios, operações e instrumentos" com os quais os meios de comunicação selecionam quotidianamente, "entre um número imprevisível e indefinido de fatos, uma quantidade finita e relativamente estável de notícias".

Os "valores-notícia" seriam uma componente da noticiabilidade e derivariam de pressupostos tais como as características das notícias e seu conteúdo, critérios relativos ao produto, ao público e à concorrência. Em relação à notícia, estariam em jogo o grau e nível hierárquico 
dos indivíduos envolvidos no acontecimento, 0 interesse nacional, a quantidade de pessoas que 0 acontecimento envolve, a relevância e a importância do acontecimento quanto à evolução futura de uma determinada situação (WOLF, 2009, p. 200-205). No período observado, houve uma reprodução de tais padrões na web.

Manchetes de $O$ Globo como Juiz decreta prisão preventiva de atirador norueguês (dia 25/7), Indicados para os Transportes devem ter ficha limpa, avisa Dilma (dia 26/7), Após queda recorde de ontem, dólar começa a subir com MP do governo (dia 27/7), Índice de inflação que reajusta aluguéis tem mais um mês de queda (dia 28/7), e Voo 44\%: novo relatório enfatiza erro dos pilotos e faz dez recomendações de segurança (dia 29/7) confirmam que os critérios como abrangência, nível hierárquico, interesse nacional e capacidade de desdobramento do noticiário foram contemplados. No Extra, as manchetes Haja imposto... só a partir de hoje brasileiro passa a ser dono de seu próprio salário (dia 30/5), Novas unidades do Senai ampliam oferta de cursos profissionalizantes no Rio (dia 31/5), Projeto prevê a venda de remédio a preço de custo para aposentados (dia 3/6) também contemplaram os valores-notícia acima mencionados presentes na cultura profissional dos jornalistas.

Assim como o mix de notícias escolhidas para serem publicadas nas inúmeras capas editadas por Cláudia e Patrícia confirmam o exercício de poder do gatekeeper, os motivos pelos quais deixaram de publicar algumas delas também o sustentam. Entre as notícias recusadas no período em $O$ Globo estavam: Estreia de Capitão América tira Harry Potter do topo das bilheterias (25/7), Pai de Amy Winehouse planeja criar fundação para ajudar viciados (27/7), Princípio de incêndio em Copacabana é controlado por funcionários de loja (28/7) e IPC-S tem deflação de 0,11\% na terceira semana de julho (25/7).

As explicações de Cláudia para a recusa foram as seguintes: em relação ao filme Capitão América e ao pai da cantora Amy Winehouse anunciando uma instituição para a recuperação dos dependentes químicos, ela foi taxativa: as notícias eram "velhas". Quanto à deflação no IPC-S, ela explicou que 0 índice não é muito utilizado e que o mês ainda não tinha terminado para se chegar a qualquer conclusão, ou seja, a notícia não teria desdobramento. 0 mesmo diagnóstico foi empregado para 0 incêndio controlado no bairro de Copacabana: "sem consequência".

No site do Extra, o índice de recusa foi particularmente alto no dia 2/6: 12 notícias "vendidas" para a capa do site não foram "chamadas". Duas delas versavam sobre 0 Fashion Rio, evento de moda que acontece duas vezes por ano no Rio de Janeiro. Ao recusar as notícias, Patrícia estava contemplando o valornotícia segundo o qual o noticiário deve ser 
equilibrado, pois já havia uma fotogaleria na capa do site sobre a feira (WOLF, 2009). Três notícias foram recusadas por serem "sem consequência": Troca de tiros em Piedade na tentativa de invasão de uma casa, Esfaqueado na Ilha do Governador e Bope faz operação no Caju. Uma outra, sobre um recall de baterias de notebook, não foi aproveitada por ser "pouco abrangente". Já a notícia sobre um ator do seriado Dallas promovendo um leilão de móveis e antiguidades foi recusada por ser "velha". Ou seja, ao recusá-las, a editora de capa estava exercendo seu papel de gatekeeper, atenta aos valores-notícia sobre a abrangência, atualidade e capacidade de desdobramento do noticiário.
Wolf (2009) observa que há critérios de noticiabilidade relacionados ao produto que dependeriam da disponibilidade e acessibilidade do meio para cobrir um acontecimento. Ele destaca a brevidade - tendo em vista critérios de espaço e tempo de que dispõem os jornais e programas de rádio e TV - e a atualidade. Entretanto, na internet, não há grades de programação, como no rádio e na TV, tampouco o ciclo de $24 \mathrm{~h}$ de produção dos jornais. Portanto, o critério atualidade, livre de qualquer constrangimento temporal, é exacerbado. As homes dos jornais são atualizadas, em média, a cada 10 minutos e meio em $O$ Globo (Tabela 3), e a cada 12 minutos no Extra (Tabela 4).

Tabela 3 - Intervalo de atualização da capa de 0 Globo*

\begin{tabular}{|c|c|c|c|}
\hline Data & $\begin{array}{c}\text { Quantidade de } \\
\text { capas editadas }\end{array}$ & Capas editadas/hora & Intervalo de atualização \\
\hline $25 / 7$ & 25 & 6,25 & 9,6 \\
\hline $26 / 7$ & 23 & 5,75 & 10,4 \\
\hline $27 / 7$ & 21 & 5,25 & 11,4 \\
\hline $28 / 7$ & 21 & 5,25 & 11,4 \\
\hline $29 / 7$ & 24 & 6 & 10 \\
\hline TOTAL & $\mathbf{1 1 4}$ & $\mathbf{5 , 7}$ & $\mathbf{1 0 , 5}$ \\
\hline
\end{tabular}

*A tabela foi construída a partir da contagem da quantidade de vezes em que a capa foi atualizada entre os dias 25 e 29/7 de 2011.0 número foi dividido pelo período de tempo em que as atualizações ocorreram (de $8 \mathrm{~h}$ às $12 \mathrm{~h}$ ).

Tabela 4 - Intervalo de atualização da capa do Extra*

\begin{tabular}{|c|c|c|c|}
\hline Data & $\begin{array}{c}\text { Quantidade de } \\
\text { capas editadas }\end{array}$ & Capas editadas/hora & Intervalo de atualização \\
\hline $30 / 5$ & 22 & 5,5 & 10,9 \\
\hline $31 / 5$ & 17 & 4,25 & 14,11 \\
\hline $1 / 6$ & 23 & 5,75 & 10,43 \\
\hline $2 / 6$ & 19 & 4,75 & 12,63 \\
\hline $3 / 6$ & 18 & 4,5 & 13,33 \\
\hline TOTAL & $\mathbf{9 9}$ & $\mathbf{4 , 9 5}$ & $\mathbf{1 2 , 1 2}$ \\
\hline
\end{tabular}

*A tabela foi construída a partir da contagem da quantidade de vezes em que a capa foi atualizada entre os dias 30/5 e 3/6 de 2011. 0 número foi dividido pelo período de tempo em que as atualizações ocorreram (de $8 \mathrm{~h}$ às 12h). 


\section{Gatekeeper ou gatewatcher?}

Já foi mencionado que faz parte do dia a dia de Cláudia e Patrícia checarem o tempo todo os sites da concorrência para verificar não só se estão sendo "furadas", mas também para buscar conteúdos de interesse do público. ${ }^{9}$ Estaria 0 papel do jornalista on-line se reconfigurando a tal ponto a transformá-lo em gatewatcher? 0 neologismo foi criado por Bruns (2005), para quem a internet permitiu a criação e denominação do que chama gatewatching. Ele põe em xeque a função dos jornalistas em ambientes interativos. Nem o gatekeeper, que seleciona e edita as notícias, nem simplesmente o bibliotecário, que organiza conteúdos para o público: 0 jornalista da web seria uma espécie de vigia. Caberia a ele observar os "portões de saída" de sites de veículos tradicionais e não tradicionais, de fontes primárias da informação, buscando conteúdos relevantes assim que eles se tornam disponíveis para redirecioná-los aos seus leitores.

Eles observam que material está disponível e é interessante e identificam novas informações úteis com o objetivo de canalizar este material para atualizar e formatar notícias que podem apontar caminhos para conteúdos de relevância $^{10}$ (BRUNS, 2005, p. 18, tradução nossa).

Primo e Träsel (2006), analisando a teoria do gatewatching, observam que, devido ao fluxo abundante de informações na internet e à falta de limitação de espaço para publicá-las, a função de avaliá-las torna-se mais necessária do que a de descartá-las: "nota-se um deslocamento da coleta de informação para a seleção da mesma". Para os autores, o gatewatcher combinaria funções de bibliotecário e repórter. "Do porteiro, passa-se ao vigia" (PRIMO; TRÄSEL, 2006, p. 37-56).

Nos sites de $O$ Globo e do Extra, as editoras também exercem o papel de gatewatcher, como foi possível constatar. A todo instante, elas checam portais e sites da internet para verificar se a concorrência está dando destaque para alguma notícia ainda não disponível nos sites que editam com o objetivo de também oferecêlas ao seu público. Quando isso acontece, porém, as editoras não as republicam sem antes checar sua procedência. No dia 26 de julho, Cláudia leu no site G1 que o Diário Oficial publicara a exoneração do assessor especial do Departamento Nacional de Infraestrutura de Transportes naquele dia. Imediatamente pediu à repórter de plantão na editoria de País que checasse a informação com a sucursal de Brasília. Somente publicou a notícia na capa do site depois de ter recebido a confirmação. 0 mesmo aconteceu no dia seguinte. Cláudia leu no portal Globo.com que a queda de um avião militar no Marrocos matara 78 e, em seguida, solicitou

Ser "furado" é um jargão jornalístico para indicar que a concorrência publicou uma notícia em primeira mão.

"They observe what material is available and interesting, and identify useful new information with a view to channeling this material into structured and up-to-date news reports which may include guides to relevant content and excerpts from the selected material." 
a confirmação à editoria de Mundo. Assim que a obteve, deu destaque a ela na capa.

No Extra, foi constatada conduta semelhante. Na manhã do dia 31/5, Patrícia leu no site de $O$ Globo a notícia Operação para prender assassino de PM deixa quatro mortos no Rio. 0 site do Extra publicara a notícia sobre a ação policial, mas não conseguira checar as quatro mortes. A editora optou, então, por reproduzir a notícia do site de $O G l o b o$, atribuindo a procedência ao jornal. Somente quando a informação sobre os mortos chegou à redação é que a reportagem de $O$ Globo foi substituída pela do Extra.

Ou seja, mesmo quando agem como gatewatcher, as editoras não abandonam seu papel de gatekeeper. As duas teorias juntas, porém, não dão ainda conta da reconfiguração do papel do jornalista na internet, pois ele também exerce 0 papel de mediador entre as notícias e seu público. Para Pavlik (2001), os papéis do jornalista no mundo analógico se restringiam a reportar os fatos, interpretar os impactos que teriam na sociedade e fixar uma agenda para 0 debate público, ajudando na construção da opinião pública. Agora, defende o autor, eles precisarão ir além: os jornalistas on-line terão um papel central na ligação entre as comunidades.

0 acesso ilimitado à informação, a interatividade em tempo real e o direito à publicação estendido a todos podem parecer, à primeira vista, as grandes vantagens da $w e b$.
Contudo, essas acabam se tornando também suas maiores desvantagens, observa Serra (2003, p. 43): "Como distinguir, no oceano de informação que vai sendo produzido e lançado, para não dizermos despejado na rede, a que é crível da que não o é?". Para 0 autor, a web fortalece 0 já consagrado papel social do jornalista como mediador.

Contrariamente à idéia de que a web dispensaria toda e qualquer mediação humana em relação à informação - e, nomeadamente, a mediação desse mediador por excelência das sociedades modernas que é o jornalista - ela reforça mesmo a necessidade dessa mediação (SERRA, 2003, p. 45).

Há quem sustente, ao contrário, que a web trouxe 0 fenômeno da desintermediação. 0 acesso irrestrito a qualquer tipo de conteúdo dispensaria o papel do jornalista como seletor, organizador e hierarquizador das informações. É o caso de Jim Hall (2001), para quem os papéis que o jornalismo atribuiu a si mesmo, com sua profissionalização no século XIX, estariam em risco a partir do momento em que as audiências passaram a ter acesso às fontes primárias de informação. Entre eles, 0 de gatekeeper e o de agenda-setter. Todavia, mesmo decretando o risco de extinção desses papéis e, consequentemente, 0 de mediador, 0 autor ainda enxerga uma função para os jornalistas. Caberia a eles serem cartógrafos, traçando mapas de navegação para seu público. Não seria o mesmo que selecionar, chancelar e recomendar informações para as audiências? 
Além de Pavlik e Serra, já mencionados, diversos outros autores (AROSO, 2005; COLOMBO, 1998; FULTON, 2000; MILLISON, 1999; MORETZSOHN, 2002; WOLTON, 2010) defendem o resgate e a revalorização da mediação dos jornalistas na web. Para Moretzsohn (2002, p. 173), "é inevitável sublinhar o papel decisivo do jornalismo como prática de mediação discursiva: é através dela que podemos tomar conhecimento do que ocorre no mundo". Fulton (2000) segue na mesma linha, ao afirmar que nem o jornalismo nem o jornalista desaparecerão. Para a autora, são os jornalistas que fornecem significado e contexto para todo 0 ruído que trafega na web e, por isso, eles podem se tornar mais essenciais do que nunca.

Millison (1999, tradução nossa) defende argumentos semelhantes: "Agora, mais do que nunca, precisamos de jornalistas profissionais que ajudem a distinguir 0 trigo de notícias de confiança e opiniões críveis do joio de rumores e propaganda que abundam na internet". ${ }^{11}$ Aroso (2005, p. 4), ao confrontar diversos autores, chega à conclusão de que "com 0 jornalismo on-line ocorre uma revalorização da mediação do jornalista. Saber explicar e dar uma interpretação dos acontecimentos será algo cada vez mais valorizado". Wolton (2010, p. 72) é outro autor que sustenta que a necessidade da mediação jornalística é diretamente proporcional à abundância de informação. Quanto maior a quantidade de informação acessível e gratuita, maior será a demanda por jornalistas "para selecionar, hierarquizar, verificar, comentar, legitimar, eliminar e criticar". Para ele, a web só reforça 0 "papel essencial da profissão de intermediário, que muitos querem suprimir em função de uma suposta democracia direta".

$$
\begin{aligned}
& \text { A democracia não é a supressão dos serviços } \\
& \text { e profissões intermediários, mas a validação de } \\
& \text { seus papéis e a capacidade de criticá-los. Os jor- } \\
& \text { nalistas são intermediários e contrapoderes [...] } \\
& \text { Contra os incontáveis poderes e contra o lobby } \\
& \text { dos que pretendem 'verificar' a informação ou } \\
& \text { entregá-la pronta; e em relação aos receptores, } \\
& \text { que não desejam, na maior parte do tempo, } \\
& \text { ouvir o que contraria suas escolhas (WOLTON, } \\
& \text { 2010, p. 72-73). }
\end{aligned}
$$

Ao mesmo tempo em que reforça o papel do jornalista como mediador, a internet também 0 alarga. Como analisa Canavilhas (2003, p. 65), "no webjornalismo, a notícia deve ser encarada como o princípio de algo e não um fim em si própria, deve funcionar apenas como o 'tiro de partida' para uma discussão com os leitores". A possibilidade de comentar, dar notas e ranquear as notícias abre fóruns que podem retroalimentar o processo de edição, cada vez mais dinâmico e circular. Desta forma, a participação do público pode vir a atenuar os constrangimentos organizacionais herdados do modelo de produção dos meios de comunicação de massa. 
0 julgamento da audiência afeta diretamente a edição das homes de $O$ Globo e do Extra. Durante os cinco dias de observação, todas as notícias que entraram na lista de mais lidas foram chamadas na capa de ambos os sites. Cláudia explica como 0 público influencia seu trabalho:

Se uma matéria é a mais lida do dia, mesmo que tenha sido publicada na véspera, em geral será eliminada da home por último. 0 ranking dos leitores também pode pautar eventuais "suítes"12 sobre o tema. Porém, não nos pautamos exclusivamente por isso. Se um assunto é importante, mesmo que tenha baixo índice de leitura, será chamado. Procuramos mesclar a necessidade de audiência com o perfil do jornal. ${ }^{13}$

Algumas das notícias mais lidas já estavam publicadas na capa antes de entrarem na lista. Porém, as editoras, sempre atentas aos rankings, logo percebiam quando a lista mudava e tratavam de checar se estavam dando às novas notícias da lista o devido destaque. Coincidentemente, na semana observada, as preferidas do leitor não feriram seus critérios editoriais.

\section{0 jornalista como mobilizador da audiência}

0 fato é que os canais interativos acabam testando os limites da simples mediação e, por conseguinte, do jornalístico. Com ferramentas tais como enquetes e editorias dedicadas exclusivamente à participação do leitor, as editoras dos sites de $O$ Globo e do Extra não raro transformam a manifestação do público em notícia. Durante a semana pesquisada, a opinião do público virou motivo de algumas chamadas na capa do site de O Globo. Uma delas - Leitores pedem renovação na seleção que será convocada hoje (dia 25/7) - era fruto de uma enquete que conclamara 0 público a opinar sobre a convocação da seleção brasileira de futebol. Uma segunda - Polêmica nos condomínios: uso de salões de festa, churrasqueiras e academias pode ser cobrado? pedia a manifestação dos leitores sobre 0 assunto.

No site do Extra, o público também foi o alvo principal de chamadas publicadas na home. Duas delas pediam aos leitores que enviassem suas perguntas para 0 cantor Latino e para 0 protagonista da novela Malhação, Bruno Gissoni, que as responderiam, respectivamente, nas seções "Você entrevista" (30/5), e na "Sessão Twitta" (2/6). No dia 31 de maio, numa clara amostra de como o jornalismo se tona permeável à publicidade, o público foi convidado a participar de um concurso para concorrer a uma prancha autografada pelo cantor Jack Johnson e a ingressos para o show que ele faria no Rio. Para participar, o leitor deveria se tornar fã da página do jornal na rede social Facebook e publicar uma "frase criativa" com os termos "Jack Johnson", "música" e "surfar". Aqui, a estratégia do Extra era clara: através da promoção, atrair mais seguidores 
para a sua página no Facebook, em que também são publicadas as notícias do jornal que, por sua vez, poderiam despertar 0 interesse do público para 0 site, aumentando, assim, a audiência.

Em outra chamada em sua home, Zé Lador vai conferir sujeira em rua de Ramos, o público novamente estava por trás da notícia. 0 Zé Lador, apelidado pelo jornal de "o super-herói do Extra", é um boneco levado pela equipe de reportagem até locais que sofrem com o descaso do poder público. À medida que os leitores enviam suas denúncias, 0 Zé Lador vai até o local "conferi-las". Lá, uma foto do boneco junto aos moradores é tirada e depois publicada no blog do Zé Lador. Ato contínuo, a equipe de reportagem aciona as autoridades responsáveis, pressionando o poder público a solucionar os problemas.

Nessas ocasiões, Cláudia e Patrícia parecem estar exercendo um papel acentuado pela internet e que provoca o esgarçamento do conceito da objetividade do qual o jornalista predominantemente se nutriu desde sua profissionalização, no século XIX: 0 de mobilizador da audiência. Pareceu-me necessário 0 aprofundamento da investigação em torno desta função que a internet propõe. Assim, para aumentar a amostragem e para confirmar a hipótese sobre a consolidação deste papel, a coleta de material prosseguiu durante os dias úteis dos meses de agosto e setembro de 2011, no mesmo período, das $8 \mathrm{~h}$ às $12 \mathrm{~h}$. Desta vez, a cada hora, as homes dos sites de $O$ Globo e do Extra eram acessadas em busca de notícias que tivessem como premissa buscar o envolvimento dos leitores.

É importante ressaltar que foi desconsiderada a área exclusivamente dedicada à participação da audiência na capa de $O$ Globo, denominada de "Eu-repórter". Ali, diariamente são publicadas notícias, fotos e vídeos enviados por leitores. É uma área demarcada dentro da capa. Por "decreto editorial", os leitores têm ali seu espaço garantido. Interessava antes investigar o restante da capa, na qual a manifestação do público disputa espaço editorial com o jornalismo profissional. Diversas outras seções e editorias de ambos os jornais na internet são abertas à participação do público. 0 foco desta pesquisa deteve-se nas homes por um motivo muito simples: assim como no jornal impresso, a primeira página na internet é considerada o espaço mais nobre. E é justo neste espaço mais valorizado que observase a elasticidade nos papéis tradicionalmente desempenhados pelos jornalistas. Ali, o editor de capa tem autoridade para decidir o que será publicado e suas escolhas se baseiam, como já visto anteriormente, num leque de notícias produzidas pelos repórteres, vindas de agências de notícia, de assessorias de imprensa, dos outros meios de comunicação, das redes sociais e do público. Quando escolhe dar voz à manifestação do público, o editor da capa necessariamente está preterindo o restante do material.

Desta maneira, busca engajar seu público em determinadas causas. Muitas vezes, esse papel 
se parece com o de "um animador de auditório", embora essa definição dependa da importância da questão social na cena política; ou seja, " $d a$ causa a ser abraçada", nas palavras de Cláudia. ${ }^{14}$ No Extra, a mobilização do público em torno de celebridades aproximou a editora muitas vezes da função de animadora. Em uma das chamadas coletadas no período observado, os leitores eram convidados a votar numa enquete: Escolha o gato que vai estampar o próximo pôster da Canal Extra (19/9). ${ }^{15}$ Quatro opções de atores eram relacionadas para que o leitor desse seu voto. Em outras duas, os leitores eram convidados a mandarem suas perguntas para as atrizes Nathalia Dill (em 5/9) e Regiane Alves (em 26/9), que as responderiam na seção "Você entrevista".

Na mesma linha, o Extra novamente abriu espaço editorial em sua capa para anunciar uma promoção convocando o público, como já fizera por ocasião do show de Jack Johnson, anteriormente mencionado. Desta vez, no dia 29 de setembro, anunciou, em uma chamada editorial, o projeto Extra Conectado: Quer participar do site do Extra e ganhar até $R \$$ 10 mil? 0 concurso selecionaria oito jornalistas amadores, que ganhariam um smartphone e teriam a missão de, durante um mês, mandar vídeos, fotos, textos, comentários e qualquer outro conteúdo para um ambiente especial no site do Extra. Além disso, era oferecido o prêmio em dinheiro. Há os que vêem esse afrouxamento dos critérios jornalísticos como uma queda entre as fronteiras do jornalismo com a publicidade:

A contaminação e a deterioração do conceito clássico de jornal diz respeito aqui, sobretudo, à promiscuidade existente entre informação e propaganda, em que as notícias dos jornais perdem sua missão precípua de reportar e passam a carregar os interesses de propagandear produtos, idéias ou personagens, numa radical inversão de valores (MARSHALL, 2003, p. 41).

Por outro lado, o Extra também mobilizou o público em torno de causas cidadãs. A representação dos leitores na capa do site foi garantida novamente pela ação do boneco Zé Lador. Por duas vezes, Patrícia destacou as conquistas do personagem em prol da comunidade nas chamadas Zé Lador extermina poça de esgoto em Piedade (10/9) e Zé Lador denuncia falta d'água em Queimados (20/9).

Cabe aqui ressaltar que não é a primeira vez que o jornalismo se afastou dos preceitos da objetividade que se consolidaram desde sua profissionalização. É possível identificar pelo menos dois momentos históricos em que a profissão se afastou deliberadamente deste caminho, seja para abraçar a prática de um estilo mais subjetivo e autoral - como no movimento que ficou conhecido como Novo Jornalismo, nos anos 1960, nos EUA -, seja para mobilizar leitores para 
determinadas causas, como no Jornalismo Cívico, nos anos 1990.

No Novo Jornalismo, em vez de assumir uma posição distanciada, o jornalista, ao contrário, deveria registrar suas observações pessoais em suas reportagens, assumindo um texto mais autoral. 0 movimento, ancorado em obras de autores como Truman Capote, Norman Mailer, Gay Talese e Tom Wolfe, deslocou a autenticidade da narrativa do relato impessoal e distante para 0 testemunho do autor, observa Jaguaribe (2007). 0 Jornalismo Cívico também levou ao questionamento do conceito de objetividade. 0 movimento contou com a adesão de quase 30 jornais regionais dos EUA, que passaram a convocar a população para assembleias públicas, nas quais as autoridades eram questionadas sobre os problemas comunitários. Rosen e Merritt, idealizadores do movimento, não hesitaram em atacar a objetividade no jornalismo. Para Merritt (1995 apud TRAQUINA, 2003, p. 13), o jornalista deveria deixar para trás a noção do "observador desprendido" e assumir 0 papel de "participante justo".

Ao refletir sobre suas funções como editora da capa do site de $O$ Globo, Cláudia concorda que exerce o papel de mobilizadora da audiência em suas rotinas profissionais, entre os demais herdados do jornalismo off-line e os que surgiram com a internet. Para ela, isso não significa abandonar o conceito do jornalista como

observador desinteressado tampouco tomar partido:

0 jornalista on-line tem a obrigação de mobilizar o público, mas também de dar visibilidade ao fruto desta participação da audiência. 0 engajamento do público pode gerar um material riquíssimo, que é um termômetro da cidadania, do que as pessoas estão pensando sobre aquilo, como reagiram, que soluções dariam para aquele problema. Essa interação com os internautas muda 0 conceito de que 0 jornalista deve ser apenas um observador distante dos fatos. Isso não significa que estejamos tomando partido, e sim estimulando o desenvolvimento de uma visão mais crítica sobre os fatos. As pessoas têm ânsia de falar na internet. 0 bom jornalista tem que saber associar os fatos e orquestrar essas falas. Não tenho a menor dúvida de que é possível engajar a audiência. ${ }^{16}$

Patrícia não considera que haja novidade no papel do jornalista como mobilizador de audiência. Mas ela acredita que a internet, ao facilitar a comunicação do leitor com o jornalista e entre os próprios leitores, acaba contribuindo para um maior envolvimento do jornalista com seu público, tirando-o de uma posição de árbitro distante dos fatos:

Mobilizar sempre foi um papel do jornalista, mas a internet intensificou essa função, ao dar um rosto ao leitor e mais agilidade nas respostas. Antes, o leitor era uma categoria genérica nas redações. Agora, sabemos o que pensa, 0 que busca. 0 jornalista, quando mobiliza sua audiência, tenta dar voz à população para determinado problema e pressiona as instituições a resolvê-lo. ${ }^{17}$ 
Numa perspectiva otimista, Kovach e

Rosenstiel (2004, p. 207) acreditam que todas as formas usadas nas práticas jornalísticas podem estimular a participação e 0 julgamento do público, criando fóruns de discussão com múltiplas vozes que ajudarão a compreender a natureza da opinião pública sobre determinados assuntos:

Todas as formas usadas pelos jornalistas no dia a dia podem servir para essa função: a de criar fóruns, ao alertar o público para temas que de certa forma estimulam julgamentos [...] À medida que essas vozes são ouvidas por aqueles que estão no poder, elas permitem entender a natureza da opinião pública em relação ao assunto em pauta. É esse processo que recria todos os dias, nas sociedades modernas, os antigos fóruns nos quais as primeiras democracias do mundo se formaram.

Ao lembrar o jornalismo cívico dos anos 1990 e trazer à tona este novo jornalismo engajado exacerbado pela internet, o propósito desta pesquisa foi revelar o quanto este papel do jornalista como mobilizador de audiência está ganhando relevância entre os demais que prevaleceram até aqui. É claro que as "causas" pelas quais o jornalismo pretende se transformar em um instrumento de mobilização social podem variar e ter amplos aspectos. Nessa perspectiva, podem servir como instrumento de mera distração, mas também como meio de pressão do poder público. Numa visão de equilíbrio, podem estar simplesmente cumprindo um relevante papel de serviço público, dando voz às reivindicações da população.

\section{Considerações finais}

Assim como a internet traz uma nova camada de informações ao jornalismo on-line, que é absorvida aos processos tradicionais de apuração, edição e distribuição da notícia, ela também superpõe camadas funcionais aos jornalistas. Se a interatividade - proporcionada por ferramentas como blogs e canais de participação destinados ao público - adiciona um fluxo de notícias complementar, sem anular o anterior, observase também que novas funções se incorporam às antigas nas redações.

Nenhuma das funções anteriores do jornalista desaparece, embora algumas tenham se afrouxado, como é o caso do gatekeeping. Na internet, as regras são mais flexíveis e a hierarquia é mais frouxa. A ação de gatekeeping é apenas uma das faces de um processo complexo e não dá conta de explicar as demais funções que estão reconfigurando o papel do jornalista na internet. 0 conceito do gatewatching tampouco. Seria reducionista imaginar que cabe a esse jornalista ser um mero observador e facilitador do acesso à informação na web. 0 processo de gatewatching se superpõe ao de gatekeeping. Entretanto, nem mesmo os dois juntos abarcam todas as funções do jornalista na $w e b$, pois ele também exerce o papel de mediador entre as notícias e seu público. Mas o próprio conceito de mediação se alargou. A possibilidade de comentar, dar notas e ranquear as notícias abre fóruns de discussão entre os jornalistas e sua audiência que podem retroalimentar o processo de edição. 
É neste ponto, face a face com seu público, que o jornalista on-line oscila entre a função de entreter e mobilizar sua audiência. Dependendo dos anseios dos leitores, ora toma 0 atalho da distração, ora tenta engajar seu público em torno de causas cidadãs. 0 papel de mobilizador de audiência poderá reabilitar o jornalismo? Para que a função de mobilizador faça sentido é preciso avaliar a repercussão de suas ações. Observar atentamente de que maneira a audiência está reagindo pode ser uma pista para definir em que medida o jornalista está se aproximando de um animador ou de um mobilizador, de fato.

\section{Referências}

AROSO, I. M. M. A internet e o novo papel do jornalista. Biblioteca on-line de Ciências da Comunicação. 2005. Disponível em: < http://www.bocc. ubi.pt/pag/aroso-ines-internet-jornalista.pdf $>$. Acesso em: 2 out. 2011.

BOWMAN, S.; WILLIS, C. Nosotros, el medio. The Media Center, 2003. Disponível em: < http://www. hypergene.net/wemedia/espanol.php $>$. Acesso em: 20 nov. 2010.

BREED, W. Controlo social na redacção: uma análise funcional. In: TRAQUINA, N. (Org.). Jornalismo: questões, teorias e "estórias". Lisboa: Vega, 1999.

BRUNS, A. Gatewatching: collaborative online news production. New York: Peter Lang, 2005.

CANAVILHAS, J. Webjornalismo: considerações gerais sobre o jornalismo na web. In: FIDALG0, A.; SERRA, J. P. (Org.). Informação e Comunicação online. Jornalismo online. Covilhã: Universidade da Beira Interior, 2003. v. 1. p. 63-74. Disponível em: < http:// www.livroslabcom.ubi.pt/pdfs/fidalgo_serra_ico1 jornalismo_online.pdf > . Acesso em 10 ago 2014.
COLOMBO, F. Conhecer o jornalismo hoje. Lisboa: Editorial Presença, 1998.

\section{FULTON, K. News isn't always journalism.}

Fathom.com, 2000. Disponível em: < http://www. fathom.com/feature/35629/index.html>. Acesso em: 2 out. 2011.

HALL, J. Online Journalism: a critical primer. London: Pluto Press, 2001.

JAGUARIBE, B. 0 choque do real. Rio de Janeiro: Rocco, 2007.

KOVACH, B.; ROSENSTIEL, T. Os elementos do jornalismo. São Paulo: Geração Editorial, 2004.

MARSHALL, L. 0 jornalismo na era da publicidade. São Paulo: Summus, 2003.

MC GARRY, K. 0 contexto dinâmico da informação. Brasília: Briquet de Lemos, 1999.

\section{MEEKER, M.; WU, L. Internet Trends D11}

Conference. 2013. Disponível em: < http:// pt.slideshare.net/kleinerperkins/kpcb-internettrends-2013>. Acesso em: 20 set. 2013.

MILLISON, D. The journalist of tomorrow. Speakout.com, 1999. Disponível em: < http:// speakout.com/activism/opinions/4171-1.html > . Acesso em: 2 out 2011.

MORETZSOHN, S. Jornalismo em "tempo real": 0 fetiche da velocidade. Rio de Janeiro: Revan, 2002.

PALACIOS, M. Jornalismo online, informação e memória: apontamentos para o debate. In: FIDALGO, A.; SERRA, J. P. (Org.). Informação e Comunicação online. Jornalismo online. Covilhã: Universidade da Beira Interior, 2003. v. 1. p. 75-89. Disponível em: <http://www.livroslabcom.ubi.pt/pdfs/fidalgo_serra ico1_jornalismo_online.pdf $>$. Acesso em: 10 ago 2014.

PAVLIK, J. V. Journalism and new media. New York: Columbia University Press, 2001.

PRIMO, A.; TRÄSEL, M. Webjornalismo participativo e a 
produção aberta de notícias. Contracampo, Niterói, v. 14, p. 37-56, 2006.

SERRA, J. P. A transmissão da informação e os novos mediadores. In: FIDALGO, A.; SERRA, J. P. (Org.).

Informação e Comunicação online. Jornalismo

online. Covilhã: Universidade da Beira Interior, 2003. v. 1. p. 13-48. Disponível em: < http://www.livroslabcom. ubi.pt/pdfs/fidalgo_serra_ico1_jornalismo_online. pdf> . Acesso em 10 ago 2014.

TRAQUINA, N.; MESQUITA, M. Jornalismo cívico. Lisboa: Livros Horizonte, 2003.

TRAQUINA, N.; MESQUITA, M. Teorias do jornalismo I: porque as notícias são como são. Florianópolis: Insular, 2005.

WHITE, D. 0 gatekeeper: uma análise de caso na selecção de notícias. In: TRAQUINA, N. (Org.). Jornalismo: questões, teorias e "estórias". Lisboa: Vega, 1999.

WOLF, M. Teorias da comunicação. Lisboa: Presença, 2009.

WOLTON, D. Informar não é comunicar. Porto Alegre: Sulina, 2010. 


\section{Contemporary changes} in journalism: the on-line journalist as an audience mobilizer

\section{Abstract}

The horizontal communication model of the internet has given everyone a voice, calling into question the role of the journalist and resetting his functions. This article has analyzed the productive routines in $O$ Globo and Extra brazilian's newspapers sites to see how the internet added roles to these professionals. The starting point was to review David White's pioneering study about the journalist as a gatekeeper in selecting news. The gatewatcher concept, which defines the journalist online as an observer that searchs for content to his audience, has also been applied. It was observed that, as the internet brings a new layer of information to the online journalism, it also superimposes functional layers onto old ones in the newsrooms. The increasing public participation proposes new roles to the journalists. It was possible to see how the online journalist is establishing his identity based on a new pillar: as an audience mobilizer, working to achieve the public's engagement.

\section{Keywords}

Online journalism. Gatekeeper. Gatewatcher. Mobilizer.

\section{Transformaciones contemporáneas en las prácticas periodísticas: el periodista digital como movilizador de la audiencia}

\section{Resumen}

El modelo de comunicación horizontal de Internet ha dado a todos una voz, poniendo en duda el papel del periodista y requiriendo la reconfiguración de sus funciones. Este artículo analiza las rutinas de producción en los sitios web de los diarios 0 Globo y Extra para ver cómo la web ha añadido para estos roles profesionales. El punto de partida fue revisar un estudio pionero de David White sobre el periodista como gatekeeper en la selección de noticias. El concepto gatewatcher, que clasifica el periodista como observador en busca de contenido para su audiencia, también se aplicó. El Internet ofrece un nuevo nivel de información a los medios de comunicación, así como nuevas funciones a los periodistas. El aumento de la participación del público propone nuevos roles para estos profesionales. Los periodistas digitales están poniendo su identidad en una nueva fundación, la de movilizar a la audiencia, trabajando para atraer a su público en torno a diversas causas.

\section{Palabras clave}

Periodismo online. Gatekeeper. Gatewatcher. Movilizador. 


\section{Expediente}

A revista E-Compós é a publicação científica em formato eletrônico da Associação Nacional dos Programas de Pós-Graduação em Comunicação (Compós). Lançada em 2004, tem como principal finalidade difundir a produção acadêmica de pesquisadores da área de Comunicação, inseridos em instituições do Brasil e do exterior.

\section{E-COMPÓS I www.e-compos.org.br I E-ISSN 1808-2599}

Revista da Associação Nacional dos Programas

de Pós-Graduação em Comunicacão.

Brasília, v.17, n.1, jan./abri. 2014.

A identificação das edições, a partir de 2008

passa a ser volume anual com três números.

\section{CONSELHO EDITORIAL}

Afonso Albuquerque, Universidade Federal Fluminense, Brasil Alberto Carlos Augusto Klein, Universidade Estadual de Londrina, Brasil Alex Fernando Teixeira Primo, Universidade Federal do Rio Grande do Sul, Brasil Ana Carolina Damboriarena Escosteguy, Pontifícia Universidade Católica do Rio Grande do Sul, Brasi

Ana Gruszynski, Universidade Federal do Rio Grande do Sul, Brasil Ana Silvia Lopes Davi Médola, Universidade Estadual Paulista, Brasil André Luiz Martins Lemos, Universidade Federal da Bahia, Brasi Ângela Freire Prysthon, Universidade Federal de Pernambuco, Brasil Antônio Fausto Neto, Universidade do Vale do Rio dos Sinos, Brasil Antonio Carlos Hohlfeldt, Pontifícia Universidade Católica do Rio Grande do Sul, Brasil Antonio Roberto Chiachiri Filho, Faculdade Cásper Líbero, Brasi Arlindo Ribeiro Machado, Universidade de São Paulo, Brasil Arthur Autran Franco de Sá Neto, Universidade Federal de São Carlos, Brasil Benjamim Picado, Universidade Federal Fluminense, Brasil César Geraldo Guimarães, Universidade Federal de Minas Gerais, Brasil Cristiane Freitas Gutfreind, Pontifícia Universidade Católica do Rio Grande do Sul, Brasil Denilson Lopes, Universidade Federal do Rio de Janeiro, Brasil Denize Correa Araujo, Universidade Tuiuti do Paraná, Brasi Edilson Cazeloto, Universidade Paulista , Brasil

Eduardo Vicente, Universidade de São Paulo, Brasil Eneus Trindade, Universidade de São Paulo, Brasil Erick Felinto de Oliveira, Universidade do Estado do Rio de Janeiro, Brasi Florence Dravet, Universidade Católica de Brasília, Brasil Gelson Santana, Universidade Anhembi/Morumbi, Brasi Gilson Vieira Monteiro, Universidade Federal do Amazonas, Brasil Gislene da Silva, Universidade Federal de Santa Catarina, Brasil Guillermo Orozco Gómez, Universidad de Guadalajara Gustavo Daudt Fischer, Universidade do Vale do Rio dos Sinos, Brasil Hector Ospina, Universidad de Manizales, Colômbia Herom Vargas, Universidade Municipal de São Caetano do Sul, Brasil Ieda Tucherman, Universidade Federal do Rio de Janeiro, Brasil Inês Vitorino, Universidade Federal do Ceará, Brasil Janice Caiafa, Universidade Federal do Rio de Janeiro, Brasil Jay David Bolter, Georgia Institute of Technology Jeder Silveira Janotti Junior, Universidade Federal de Pernambuco, Brasi João Freire Filho, Universidade Federal do Rio de Janeiro, Brasil John DH Downing, University of Texas at Austin, Estados Unidos
José Afonso da Silva Junior, Universidade Federal de Pernambuco, Brasil José Carlos Rodrigues, Pontifícia Universidade Católica do Rio de Janeiro, Brasil José Luiz Aidar Prado, Pontifícia Universidade Católica de São Paulo, Brasil José Luiz Warren Jardim Gomes Braga, Universidade do Vale do Rio dos Sinos, Brasil Juremir Machado da Silva, Pontifícia Universidade Católica do Rio Grande do Sul, Brasil Laan Mendes Barros, Universidade Metodista de São Paulo, Brasil Lance Strate, Fordham University, USA, Estados Unidos Lorraine Leu, University of Bristol, Grã-Bretanha Lucia Leão, Pontifícia Universidade Católica de São Paulo, Brasil Luciana Panke, Universidade Federal do Paraná, Brasil Luiz Claudio Martino, Universidade de Brasília, Brasil Malena Segura Contrera, Universidade Paulista, Brasil Márcio de Vasconcellos Serelle, Pontifícia Universidade Católica de Minas Gerais, Brasil Maria Aparecida Baccega, Universidade de São Paulo e Escola Superior de Propaganda e Marketing, Brasil Maria das Graças Pinto Coelho, Universidade Federal do Rio Grande do Norte, Brasil Maria Immacolata Vassallo de Lopes, Universidade de São Paulo, Brasil Maria Luiza Martins de Mendonça, Universidade Federal de Goiás, Brasil Mauro de Souza Ventura, Universidade Estadual Paulista, Brasil Mauro Pereira Porto, Tulane University, Estados Unidos Nilda Aparecida Jacks, Universidade Federal do Rio Grande do Sul, Brasil Paulo Roberto Gibaldi Vaz, Universidade Federal do Rio de Janeiro, Brasil Potiguara Mendes Silveira Jr, Universidade Federal de Juiz de Fora, Brasil Renato Cordeiro Gomes, Pontifícia Universidade Católica do Rio de Janeiro, Brasil Robert K Logan, University of Toronto, Canadá

Ronaldo George Helal, Universidade do Estado do Rio de Janeiro, Brasil Rosana de Lima Soares, Universidade de São Paulo, Brasil Rose Melo Rocha, Escola Superior de Propaganda e Marketing, Brasil Rossana Reguillo, Instituto de Estudos Superiores do Ocidente, Mexico Rousiley Celi Moreira Maia, Universidade Federal de Minas Gerais, Brasi Sebastião Carlos de Morais Squirra, Universidade Metodista de São Paulo, Brasil Sebastião Guilherme Albano da Costa, Universidade Federal do Rio Grande do Norte, Brasil

Simone Maria Andrade Pereira de Sá, Universidade Federal Fluminense, Brasi Tiago Quiroga Fausto Neto, Universidade de Brasília, Brasil Suzete Venturelli, Universidade de Brasília, Brasil Valerio Fuenzalida Fernández, Puc-Chile, Chile Veneza Mayora Ronsini, Universidade Federal de Santa Maria, Brasil Vera Regina Veiga França, Universidade Federal de Minas Gerais, Brasil

\section{COMISSÃO EDITORIAL}

Cristiane Freitas Gutfreind I Pontifícia Universidade Católica do Rio Grande do Sul, Brasil Irene Machado I Universidade de São Paulo, Brasil

Jorge Cardoso Filho I Universidade Federal do Reconcavo da Bahia, Brasil / Universidade Federal da Bahia, Brasil

CONSULTORES AD HOC

Adriana Amaral, Universidade do Vale do Rio dos Sinos, Brasil

Alexandre Rocha da Silva, Universidade Federal do Rio Grande do Sul, Brasi Arthur Ituassu, Pontifícia Universidade Católica do Rio de Janeiro, Brasil Bruno Souza Leal, Universidade Federal de Minas Gerais, Brasil Elizabeth Bastos Duarte, Universidade Federal de Santa Maria, Brasil Francisco Paulo Jamil Marques, Universidade Federal do Ceará, Brasi Maurício Lissovsky, Universidade Federal do Rio de Janeiro, Brasil Suzana Kilpp, Universidade do Vale do Rio dos Sinos, Brasil Vander Casaqui, Escola Superior de Propaganda e Marketing, Brasil

EDIÇÃO DE TEXTO E RESUMOS I Susane Barros SECRETÁRIA EXECUTIVA I Helena Stigger EDITORAÇÃo ELETRÔNICA I Roka Estúdio
COMPÓS I www.compos.org.br

Associação Nacional dos Programas de Pós-Graduação em Comunicação

Presidente

Eduardo Morettin

Universidade de São Paulo, Brasil

eduardomorettin@usp.br

Vice-presidente

Inês Vitorino

Universidade Federal do Ceará, Brasil

ines@ufc.br

Secretária-Geral

Gislene da Silva

Universidade Federal de Santa Catarina, Brasil

gislenedasilva@gmail.com 